(6) OPEN ACCESS

\title{
Heated tobacco products: things we do and do not know
}

\author{
Irina Stepanov, ${ }^{1}$ Alistair Woodward ${ }^{2}$
}

${ }^{1}$ Masonic Cancer Center and Division of Environmental Health Sciences, University of Minnesota, Minneapolis, Minnesota, USA

${ }^{2}$ Department of Epidemiology and Biostatistics, University of Auckland, Auckland, New Zealand

\section{Correspondence to}

Dr Irina Stepanov, Masonic Cancer Center and Division of Environmental Health Sciences, University of Minnesota, Minneapolis, MN 55455, USA: stepa011@umn.edu

Check for updates

(c) Author(s) (or their employer(s)) 2018. Re-use permitted under CC BY-NC. No commercial re-use. See rights and permissions. Published by BMJ.

To cite: Stepanov I, Woodward A. Tob Control 2018;27:s7-s8.
This Special Issue is focused on IQOS, electronic devices that offer yet another nicotine delivery alternative to smoking regular tobacco cigarettes. IQOS are designed to heat rather than burn tobacco, and represent somewhat of a hybrid of a regular cigarette and an electronic cigarette. Little is known about the toxicity and the public health impact of these products, relative to both the combustible cigarettes and other nicotine delivery products. Nevertheless, IQOS and other heated tobacco products (HTPs) are gaining popularity in some countries, caused in large part by the manufacturer's aggressive advertising and assertions that these devices are safe.

Most in the public health world would agree that the best evidence-based approaches should be applied to reduce death and illness due to tobacco use. Such approaches may include supporting addicted tobacco users to move to alternatives that are less harmful and truly reduce the population burden of tobacco diseases. It is important to bear in mind these two goals - alternative tobacco delivery devices may be less risky than combustible cigarettes for the individual smoker, but if they do not lead to a reduction in the prevalence of smoking there is no gain for public health.

What do we know about the safety of IQOS and the effect that introduction of these devices may have on smoking rates and the population burden of disease and premature mortality? Unfortunately information about IQOS and similar products is, at present, largely limited to industry reports. These include observations from marketing and data from product toxicity and human exposure studies. The papers in this Special Issue take a close look at the industry material, as well as the limited emerging academic literature on HTPs. The findings in broad terms are not terribly surprising. Data are scarce, and in particular, there are no long-term studies in human populations of the consequences of use of IQOS. Nevertheless an addictive product is being promoted by over-emphasising (or in some cases exaggerating) the limited evidence for its capacity to reduce harm, while minimising evidence on its potential toxicity. A sceptical view, conditioned by history, would be that this may be part of strategic efforts by the industry to retain existing consumers of tobacco products and generate new lifelong nicotine-dependent users. We offer some suggestions about what we do not know at present about IQOS, but need to understand to best inform tobacco control policies.

Research independent of the industry is required to inform product users, public health professionals, and regulatory agencies about the potential public health impact of IQOS and other HTPs. In addition, if reports of research studies are submitted by the industry to regulatory agencies, there must be careful analysis of raw laboratory data to ensure the results are well tested and appropriately interpreted.

The chemical profile and toxicity of IQOS and other HTPs must be thoroughly investigated. It is critical to understand where these products are positioned along the continuum of risk relative not only to combustible cigarettes but also to other nicotine delivery devices that may have lower toxicity profile, such as e-cigarettes. Unlike e-cigarettes, HTPs do contain tobacco and therefore, even in the absence of combustion, are expected to deliver to their users thousands of chemicals that are present in the tobacco material. Moreover, some of the tobacco chemicals that would be partially or completely decomposed during the combustion process may be present in the emissions of HTPs. Thus, it is possible that HTPs deliver to their users a unique chemical mixture with a distinct toxicity profile. As the result, the benefits of reductions in exposure to some of the 'usual suspects', such as polycyclic aromatic hydrocarbons, may be attenuated by new health risks. Lastly, similar to e-cigarettes, IQOS and other HTPs contain substantial amounts of propylene glycol that is aerosolized when the device is in use. Oxidative stress and inflammation, some of which is most likely driven by exposures to the products of thermal decomposition of propylene glycol, are emerging as key concerns in assessing the longterm health consequences of e-cigarette use. It seems likely that users of HTPs will face similar risks, if these do indeed apply.

Characteristics of current and potential users of HTPs need to be taken into consideration while assessing the potential public health impact of these products. The concept of the continuum of harm often focuses on the toxicity profile of the product, as compared with cigarette smoke and isolated from the characteristics of the user. Similar to e-cigarettes, the relative harmfulness of HTPs may be greatly affected by whether or not a user is a former smoker, uses the product together with continued smoking of regular cigarettes, has significant co-morbidities (cardiovascular and lung diseases in particular), or a propensity to become a life-long nicotine-dependent user.

It is important to understand what HTPs will do to the prevalence of smoking. In the absence of substantial, reliable data, decisions about products such as IQOS are an exercise in risk management. On the one hand, there is the possibility of foregoing benefits (if there is a true, net reduction in harm), on the other the prospect of inflicting serious risks to health. How this balancing act is viewed will depend to some extent on context. Where the 
prevalence of smoking is already low and falling, a conservative approach to new tobacco products is understandable. Where prevalence is high, and in some population groups is hardly budging despite concerted effort, then there may a greater willingness to explore alternatives to the combustible cigarette.

Finally, we note that current smokers who are concerned about their health risks and can afford electronic tobacco or nicotine delivery devices represent only a fraction of the tobacco industry's total consumer base. Regular tobacco cigarettes are still being aggressively marketed to low-income markets worldwide, contributing to sustained tobacco consumption and the narrative of demand-driven cigarette manufacturing and sales. Once again, a history-conditioned sceptical view would be that marketing of products like IQOS is just a new way to appeal to a wider variety of nicotine consumers. Will the industry attempt to maintain their diverse consumer base by whatever means available? The most likely answer is yes, because this is what it takes to stay in the business of tobacco.

Competing interests None declared.

Patient consent Not required.

Provenance and peer review Not commissioned; internally peer reviewed.

Open access This is an open access article distributed in accordance with the Creative Commons Attribution Non Commercial (CC BY-NC 4.0) license, which permits others to distribute, remix, adapt, build upon this work non-commercially, and license their derivative works on different terms, provided the original work is properly cited, appropriate credit is given, any changes made indicated, and the use is non-commercial. See: http://creativecommons.org/licenses/by-nc/4.0/. 